\title{
Congenital dyserythropoietic anemia type IV
}

INSERM

\section{Source}

INSERM. (1999). Orphanet: an online rare disease and orphan drug data base. Congenital dyserythropoietic anemia type IV. ORPHA:293825

Cong enital dyserythropoietic anemia type IV (CDA IV) is a newly discovered form of CDA (see this term) characterized by ineffective erythropoiesis and hemolysis that leads to severe anemia at birth. 